\title{
Exploring Motivation Factors of Software Engineers in GCC Countries
}

\author{
Asaad Alzayed, PhD \\ Public Authority for Applied Education and Training (PAAET), \\ P.O.Box: 65130, Almansouriya, Kuwait 35652
}

\begin{abstract}
The failure of IT projects is an issue that organizations have continued to grapple with for many years. Much of the literature has pointed out the importance of the motivation factors for software engineers, as crucial factors that affect project outcomes. Although factors that motivate software engineers have been recognized and studied, to the best of the author's knowledge, none of the research has examined the motivation factors for software engineering practitioners within the GCC (Gulf Cooperation Council, namely Saudi Arabia (KSA), Kuwait, The United Arab Emirates (UAE), Qatar and Oman.) countries. Hence, this study aims to provide the motivation factors that influence project outcomes in GCC countries. This study explores the motivational levels of software engineers working on software development projects. A survey questionnaire was distributed to practitioners in the software engineering field to collect the data. The results suggest that motivation factors are not significantly correlated with project outcome in this region, which is different from what was found in previous studies. There are no specific motivation factors in each country. However, the findings can assist software project managers working in the GCC countries or those dealing with global software development in the same region.
\end{abstract}

\section{Keywords}

Software engineers' motivation, Software development, Team motivation, Project outcome, Motivational factors

\section{INTRODUCTION}

Motivation is considered to be an important factor for software engineers that affect practitioner productivity [1] and software quality management [2]. However, the role of the motivation is poorly understood, and it is difficult to manage [3], especially when it is not known what motivates software engineers. The reason is that they require a set of oft skills, which is important in the software development process. However, software engineering professionals often overlook these skills because they are related to social and personality factors [4]. Therefore, there is an emerging need for developing a model of motivation for software engineers [5],[6].

According to Beecham [5], motivating factors for software developers are different from the conventional motivating factors, such as rewards, recognition of efforts, and employee turnover. She also asserted that software developers find motivation in the work they do, e.g., task identification, variety of work, and career planning and in their developmental needs. In this respect, an understanding of motivational factors for software developers will play a critical role in creating better quality software, sharing skills, and increasing productivity [5].

Verner et al. [7] surveyed software developers from the US, Australia, Chile, and Vietnam, to evaluate the role of culturally dependent and independent factors on how these factors help in team motivation and understanding the relationship between these factors and project outcome. They find out that teams working in software development influence the outcome of the project. This was particularly evidenced in Chile, Australia, and the USA. In addition, the motivational factors were particular to each of the nations investigated [7]. These motivation factors include a good working environment, a project manager with good communication skills, a project in which risks were reassessed, good teamwork, a customer with confidence in the project manager and development team, and having a pleasant experience working on the project.

Culture can have a significant effect on the life and work habits of software engineers [8]. The increased tendency of using global software engineering (GSE), the desire to select offshore software engineers, and cultural differences in teams working in software development largely influence personal expectations, results, and team motivation [9].

Most of the studies on motivational factors in software engineering professionals have been conducted in Europe and America. However, there is a lack of studies evaluating the motivational factors for software engineers in the GCC countries. The Arab world consists of 22 countries, sharing similar beliefs, culture, history, language, and geographic location. GCC countries are among those countries [10]. Therefore, this study does not consider the effect of culture on motivational factors and their differences. However, there is little information on motivational factors for software engineers working in this region.

The author used the same motivational factors that were used in Verner et al. [7] to investigate the software developer's motivation level and the relationship between team motivation level and project outcome for software engineers working in GCC countries. The questionnaire used consisted of the following questions:

- RQ1: What are the motivational levels within software engineering teams in GCC countries? Are these levels similar across the six countries?

- RQ2: What is the relationship between team motivation and project outcome in GCC nations? Is the relationship similar across all nations?

- RQ3: What factors contribute to team motivation for software engineers in GCC nations? Are these software engineers motivated in a similar way for all countries?

In an exploratory analysis, responses from 163 software engineering professionals working in six GCC countries were analyzed. This study focused on motivational factors that affect software engineers within the workplace.

The research paper is organized as follows. Section 2 provides an overview of the research background, including a review of project outcomes and software engineers' motivations. Section 
3 describes the methodology. Section 4 presents the results of the study. Section 5 discusses the validity tests. Finally, the conclusion and future research are included in Section 6.

\section{LITERATURE REVIEW}

This section focuses on factors that impact project success and failure and examines elements related to the software developer's motivation within the profession.

\subsection{Project outcome}

As outlined by Shokri-Ghasabeh and Kavoousi-Chabok, [11] The success or failure of a project does not solely depend on factors such as time, quality, or cost; other factors are important as well. Different stakeholders view projects in different ways. Developers might consider the project to be a success, whereas management or users consider the same project to be a failure, or vice versa [12],[13]. Sometimes, software developers and project managers realize some kind of success that the organization may classify as partially failed [14]. Some factors that have a positive impact on software developers include a sense of achievement, delivering quality work, and presenting the managers and developers with a challenging environment to complete their work [1],[2],[12],[15].

\subsection{Motivation in software engineering literature}

Several studies analyzed the motivation of practitioners in the software industry [5],[6],[11]. It is difficult to manage human factors and motivate software engineers in software development projects. According to ProjectLink [16], it is imperative to update the old techniques used to motivate workers within an organization. In this project, much of the focus has been placed on the use of rewards and employee recognition as motivating factors. Some experts have pointed out the distinct personality profile of software engineers who find motivation from the work they do. For example, software professionals are keen on achieving success using technical skills and are motivated to solve technical problems within the project [17],[18]. Conversely, demotivation leads to project failure, including stress, unfair reward systems, inequity, poor communication, and other factors [7]. Motivators, skills, and time are crucial factors in establishing software development processes [19]. Studies have shown that motivation encompasses turnover and staff retention [20-23].

In an exploratory analysis of data from Chile, the USA, and Australia, Verner et al. [13] examined team motivation levels and investigated how motivation affects the project outcomes. It was found that the levels of team motivation are generally high for successful projects. Nevertheless, whenever there is a lack of agreement between managers and developers on the outcome of the project, developer motivation levels are noted to be the same as when the project was accepted by management and developers as a failure. Misirli et al., (2015) [24] using the same methodology of Verner et al. [7] investigated the relationship between team motivation and project outcome, as well as motivational factors for Finnish software engineers and others from the different cultural backgrounds who have lived in Finland. On comparison, the results revealed that team motivation for Finish software engineers is not correlated to project outcome; the finding was similar to that of Verner et al. [7] for the Vietnamese software engineers. A project manager with a clear vision and complete authority to oversee the project was also regarded as significant motivational factor [24, 7].

In present study the same four sets of motivational factors were applied to software engineers in GCC organizations to examine the level of motivation and the relationship between these factors and project outcomes. These factors, condensed from a prior survey [25], are related to customer relationship, development and work environment, the development process, and Project management. This study does not emphasize similarities and differences of software engineers with other professional groups. Instead, the focus of the on working of software engineering teams, relationships between the result of the project and the motivation of professionals, as well as the effect of culture on these relationships.

\section{METHODOLOGY}

This study used a survey to gauge elements, such as software development progress and team motivation, based on the perception of the engineers who participated in the research. The survey helped achieve the research objective and was a cost-effective way to access data from a sizable number of respondents. The study uses an exploratory approach

\subsection{Questionnaire design}

The study used a questionnaire used by Verner et al. [7]. However, some sections of the original questionnaire were not relevant to the current study. The original questionnaire was designed in 2000 [26], after extensive consultations with more than 90 software developers and after an extensive review of the literature, considering the factors associated with software development success and failure. Verner and Evanco published the results drawn from the questionnaire [25]. This paved the way for the creation of a short version of the original questionnaire. US developers took part in the pilot study. The questionnaire dealt with important success factors of software projects in seven broad sections, namely, management; customers and users; requirements; estimation, schedule, and staffing; the project manager; the software development process (including risk practices); and development personnel. A shortened version was created from the same questionnaire that was later reported [7],[11-13], including questions relating to motivation. The questionnaire layout focused on key features of software development. This addressed four sections, namely, project manager, software development, external project, and considerations for the practitioners. The respondents answered the questions based on their recent IT project experience. The questionnaire used a Likert-type scale and is summarized in Table 1.

Table 1. Survey questions

\begin{tabular}{|c|c|c|}
\hline \multicolumn{2}{|c|}{ Question category } & How variable was referenced \\
\hline \multicolumn{2}{|c|}{ Project management (PM) factors } & Project manager authority \\
\hline Did the PM have full authority to carry out the project? & No authority - full authority & Project manager vision \\
\hline Did the PM define vision driving the project? & No vision - completed vision & Project manager communication \\
\hline How effective is PM in communicating with staff? & Poor - good & Project manager experience \\
\hline How much experience did the PM have in managing projects? & Number of years work & . \\
\hline
\end{tabular}




\begin{tabular}{|c|c|c|}
\hline & & (years) \\
\hline How do you rate the PM? & Poor - good & Good project manager \\
\hline \multicolumn{3}{|c|}{ Software Development Factors } \\
\hline Did the project have a clearly defined scope? & Very poor - partially - very good & Scope well defined \\
\hline $\begin{array}{l}\text { Did the project's scope change while the project was under } \\
\text { way? }\end{array}$ & Extensive - partial - no change & Scope changed \\
\hline $\begin{array}{l}\text { Did the project utilize a defined development or other } \\
\text { approach? }\end{array}$ & The name of the approach & Define development methodology \\
\hline Were any potential risk identified when the project began? & No risk - all risks identified & Potential risks \\
\hline Did the project plan have any potential risks? & No risk - all risks incorporated & Risks incorporated \\
\hline Were risk assessment, control, and management carried out? & No risk - all risks controlled/managed & Risks reassessed \\
\hline \multicolumn{3}{|c|}{ External Project Factors } \\
\hline Were clients involved in the project? & No - heavy client involvement & Customer involvement \\
\hline What level of confidence did the customer exhibit? & No - high confidence levels & Customer confidence \\
\hline $\begin{array}{l}\text { Did the clients exhibit realistic expectations during the } \\
\text { project? }\end{array}$ & Unrealistic - realistic expectations & Customer expectation \\
\hline How can you rate the working environment of the project? & Poor - good & Working environment \\
\hline $\begin{array}{l}\text { Was project classified as a maintenance or development } \\
\text { project? }\end{array}$ & Maintenance - development & Project type \\
\hline \multicolumn{3}{|c|}{ Practitioner factors } \\
\hline How were team members motivated in the project? & Low - high & Team motivation \\
\hline Which areas of management was there (lack of) motivation? & All - no areas of management & Motivation/lack of motivation \\
\hline Did aggressive schedule affect motivation of the team? & Aggressive effect - no effect & Schedule effect on motivation \\
\hline Did project have enough staff to ensure that schedule is met? & Inadequate - sufficient staffing & Adequate staff \\
\hline Did staff receive appreciation for working long hours? & No - remarkable appreciation & Staff appreciation \\
\hline Did staff receive rewards for working long hours? & No - good rewards & Staff rewards \\
\hline How can you rate the turnover rate during the project? & Low turnover - no turnover & Staff turnover \\
\hline Did key personnel stay throughout the project? & Many left - all employees stayed & Key personnel stayed \\
\hline How did staff members work together on the team? & Poor - good & Teamwork \\
\hline What experience did you have as you worked on the project? & Bad-good & Pleasant staff experience \\
\hline Do you consider the project to be a success? & $\begin{array}{l}\text { Successful - partially successful - } \\
\text { failure }\end{array}$ & Project outcome \\
\hline
\end{tabular}

Respondents were asked some general questions to clarify whet her they were engaged in project development or maintenance, and about their key context in ethnic and cultural terms. Further description of the questionnaire can be found in Verner and Evanco's study [26]. The final part of the questionnaire included the evaluation of the project as successful or as a failure. Success cannot be defined in advance. However, respondents were allowed to provide their own definition of success. As highlighted by Verner and Evanco (2005)[25], project success correlates with engineers' motivation [26]. It also aligns with critical thinking. As observed by ShokiriGhasabeh and Kavoousi-Chabok [11], different stakeholders view success differently and researchers should not generalize the interpretation of project success.

\subsection{Administration of the questionnaire, selection of the participants and data collection methods}

In this study choosing a random sample was not possible. Therefore, a convenience sample was applied. Sampling convenience means choosing certain cases that are eas iest to collect and continuing until a suitable sample is collected. A convenient sample of 163 respondents returned completed questionnaires, including 37 Bahrain respondents, 36 from the Kingdom of Saudi Arabia (KSA), 12 from Kuwait, 6 from Oman, and 36 from the UAE. Each commented on various projects. There were 37 project managers, 20 customers, 28 users, 5 MIS managers, and 26 respondents working in other management positions and with applications used in educational and financial institutions in the GCC nations. The sample was 
made up of persons engaged in in-house and outsourced software development projects, all of whom had expertise in software development. To control the potential bias of inexperience in software development which could affect the results, information about the level of experience and nature of software development job performed by the respondent was also collected. The author believed that a sample of 163 participants was reasonable to conduct software engineering empirical research. Participants from GCC countries were asked to answer all 27 questions (Table 1). These practitioners were not randomly selected; a convenient sample comprising of developers who could be easily accessed was used instead.

An exploratory approach was used to analyze the study findings. The data were investigated using contingency tables, bar charts, plots, and statistical tests. The data were incorporated into two-dimensional tables, which recorded each category of frequency. The contingency tables included data about GCC software engineers and information on project type, results, and team motivation levels. The analysis includes the ordinal scale and categorical (yes/partially/no) data and suitable parametric and non-parametric statistical tests. The statistical tests help in analyzing the difference between project outcome and motivation factors among software developers in the GCC countries. Before these tests were carried out, team motivation was converted from a 5-point scale to a 3-point scale, as the data varied between 2 (low motivation) and 4 (high motivation). The participants did not use the most extreme values, such as very low or very high motivation levels.

For the first question (What are the motivation levels within software engineering teams when working on projects in the GCC countries, and are these levels similar across countries?), cross-tabulation was used to present team motivation levels for all projects. The Kruskal-Wallis test was used to find significant differences between team motivation levels within all six countries.

For the second question (What is the relationship between team motivation of software engineers and project outcomes in the GCC countries, and is the relationship similar across countries?), the chi-square test of independence was carried out to compare the finding from six countries. Respondents were placed into groups based on project success, and the MannWhitney $U$ and Kruskal-Wallis tests were carried out to ascertain if motivation levels within the groups occur with the same distribution.

For the third question (What factors contribute to software engineer motivation in the GCC countries, and are the factors the same across countries?), the chi-square test of independence was used to test if the factors in Table 1 can be considered to be motivational, which motivation factors are universal, and which factors are specific to a country. Mann-Whitney $U$ test was used, which compared medians of the provided responses for every factor examined to see if they differ among the respondents.

\section{RESULTS}

\subsection{Data overview}

This section considers all projects in the dataset that are categorized as development or maintenance and successful, partially successful, or a failure. It then discusses the motivation for each country and overall in the GCC countries. Table 2 presents the general details of the data sample. The dataset includes combined data from all six countries. A total of 127 projects were in software development $(77 \%)$ and only 36 (22\%) were in software maintenance. Table 5 shows that $75 \%$ of the projects were considered successful, $27 \%$ partially successful, and only $5 \%$ failed in all the six countries. It is clear that all the six countries considered most of their projects as successful, Qatar and KSA are the only countries that considered their projects as failed. This shows that when respondents were filling the questionnaires they may have preferred to choose successful projects rather than failed ones or else they do not like to consider a project as a failure.

Table 2: Number of respondents and project type

\begin{tabular}{|c|c|c|c|c|c|c|}
\hline Country & Projects & \multirow{2}{*}{$\begin{array}{c}\text { Respo } \\
\text { ndent } \\
\end{array}$} & & \multicolumn{2}{|c|}{ Development } & \multicolumn{2}{|c|}{ Maintenance } \\
\cline { 4 - 7 } & & No. & $\%$ & No. & $\%$ \\
\hline Bahrain & 37 & 37 & 34 & 91 & 3 & 8 \\
\hline KSA & 36 & 36 & 26 & 72 & 10 & 27 \\
\hline Kuwait & 12 & 12 & 8 & 66 & 4 & 33 \\
\hline Oman & 6 & 6 & 5 & 83 & 1 & 17 \\
\hline Qatar & 36 & 36 & 31 & 86 & 5 & 14 \\
\hline UAE & 36 & 36 & 23 & 64 & 13 & 36 \\
\hline Total & 163 & 163 & 127 & 77 & 36 & 22 \\
\hline
\end{tabular}

\subsection{Motivation levels}

In answering the first part of the first question (What are the motivation levels within software engineering teams when working on projects in the GCC countries?), motivation levels vary across the six countries (Table 3 and Figure 1).

Table 3: Team motivation: overall and by country (\%)

\begin{tabular}{|c|c|c|c|c|c|c|c|}
\hline & $\begin{array}{c}\text { Over } \\
\text { all }\end{array}$ & UAE & KSA & $\begin{array}{c}\text { Kuw } \\
\text { ait }\end{array}$ & $\begin{array}{c}\text { Qat } \\
\text { ar }\end{array}$ & $\begin{array}{c}\text { Bahr } \\
\text { ain }\end{array}$ & $\begin{array}{c}\text { Om } \\
\text { an }\end{array}$ \\
\hline Low & 34.4 & 38.9 & 33.3 & 16.7 & 19.4 & 51.4 & 33.3 \\
\hline $\begin{array}{c}\text { Averag } \\
\text { e }\end{array}$ & 34.4 & 30.6 & 50.0 & 33.3 & 30.6 & 27.0 & 33.3 \\
\hline $\begin{array}{c}\text { High } \\
\text { motiva } \\
\text { tion }\end{array}$ & 31.3 & 30.6 & 16.7 & 50.0 & 50.0 & 21.6 & 33.3 \\
\hline $\begin{array}{c}\text { Overall country } \\
\text { motivation } \\
\text { level }\end{array}$ & $\begin{array}{c}\text { Aver } \\
\text { age }\end{array}$ & $\begin{array}{c}\text { Aver } \\
\text { age }\end{array}$ & High & $\begin{array}{c}\text { Hig } \\
\text { h }\end{array}$ & Low & $\begin{array}{c}\text { Aver } \\
\text { age }\end{array}$ \\
\hline
\end{tabular}

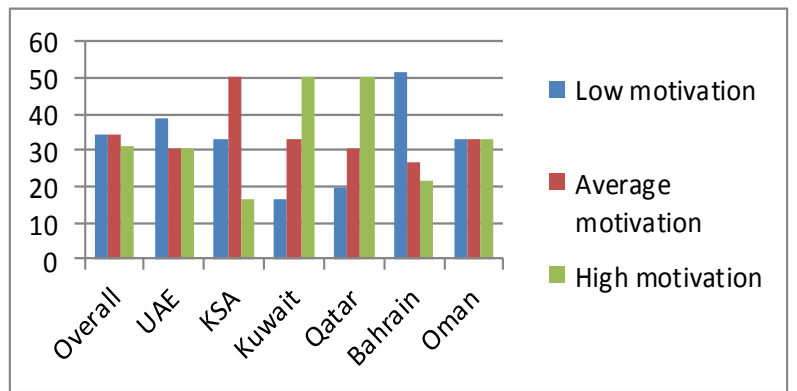

Figure 1: Team motivation: overall and by country (\%) 
The Kruskal-Wallis test was used to show whether the motivation levels are different across the countries. The test showed that there were significant differences in team motivation levels across all the countries (Kruskal-Wallis = 13.694; $p=0.018$ ). Therefore, the null hypothesis (motivation levels were the same across the GCC countries) was rejected. Kuwait and Qatar have the highest levels of motivation across all six countries, and there is no significant difference between the two $(p=0.938)$. Bahrain has the lowest level of motivation across all countries, and the mean motivational level is significantly lower than Kuwait $(p=0.024)$ and Qatar $(p=$ $0.002)$. KSA, the UAE, and Oman have average levels of motivation (Table 4).

Table 4: Median motivational level: overall and by country

\begin{tabular}{|c|c|}
\hline Country & Team motivation Median \\
\hline Overall & Average \\
\hline UAE & Average \\
\hline KSA & Average \\
\hline Kuwait & High \\
\hline Qatar & High \\
\hline Bahrain & Low \\
\hline Oman & Average \\
\hline
\end{tabular}

There are significant differences in team motivational levels for successful projects across all countries (Kruskal-Wallis $\mathrm{H}=$ 16.637; $p=0.005$ ) (Figure 2). The team motivation level in Qatar is significantly higher than the UAE, KSA, and Bahrain's ( $\mathrm{p}=0.034,0.002,0.000$, respectively) when the project is successful. Also, there is no significant difference in team motivation levels across the UAE and KSA when the project is successful. Oman was not included in the comparison test because of the small sample size.

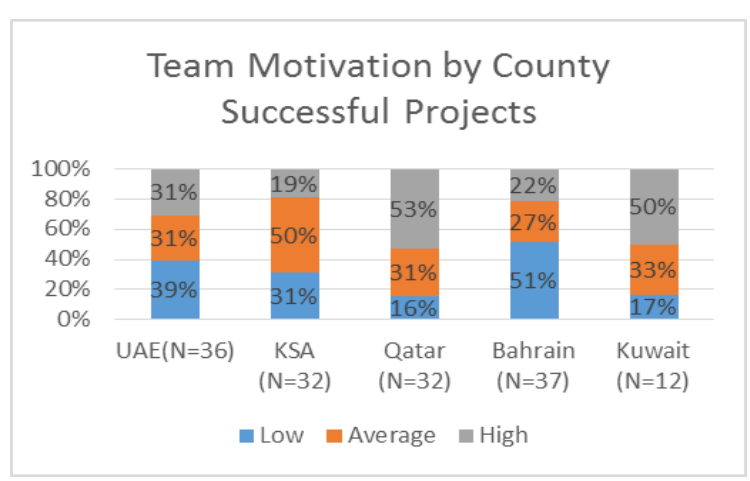

Figure 2: Team motivation with successful project by country

\subsection{Motivation levels and project outcomes}

Of the 163 respondents, 118 considered the project to be successful (72\%), 45 considered partially successful (27\%), and only 8 considered failure (5\%) (Tables 5 and 6 ).

Table 5: Number of successful, partially successful, and failed projects

\begin{tabular}{|c|c|c|c|c|c|c|c|}
\hline \multirow{2}{*}{ Country } & \multirow{2}{*}{ Total } & \multicolumn{2}{|c|}{ Successful } & \multicolumn{2}{c|}{$\begin{array}{c}\text { Partially } \\
\text { successful }\end{array}$} & \multicolumn{2}{c|}{ Failures } \\
\cline { 3 - 8 } & & No. & $\%$ & No. & $\%$ & $\#$ & $\%$ \\
\hline
\end{tabular}

\begin{tabular}{|c|c|c|c|c|c|c|c|}
\hline Bahrain & 37 & 32 & 86 & 5 & 14 & 0 & 0 \\
\hline KSA & 36 & 26 & 72 & 10 & 27 & 4 & 11 \\
\hline Kuwait & 12 & 4 & 33 & 8 & 66 & 0 & 0 \\
\hline Oman & 6 & 2 & 33 & 4 & 66 & 0 & 0 \\
\hline Qatar & 36 & 28 & 77 & 8 & 22 & 4 & 11 \\
\hline UAE & 36 & 26 & 72 & 10 & 27 & 0 & 0 \\
\hline Total & 163 & 118 & 72 & 45 & 27 & 8 & 5 \\
\hline
\end{tabular}

Table 6: Team motivation and project outcome data by country

\begin{tabular}{|c|c|c|c|c|}
\hline & $\begin{array}{c}\text { Low } \\
\text { motivation }\end{array}$ & $\begin{array}{c}\text { Average } \\
\text { motivation }\end{array}$ & $\begin{array}{c}\text { High } \\
\text { motivation }\end{array}$ & Total \\
\hline \multicolumn{5}{|c|}{ UAE } \\
\hline Success & 11 & 5 & 10 & 26 \\
\hline Partial & 3 & 6 & 1 & 10 \\
\hline Failed & 0 & 0 & 0 & 0 \\
\hline Total & 14 & 11 & 11 & 36 \\
\hline \multicolumn{5}{|c|}{ KSA } \\
\hline Success & 7 & 12 & 3 & 22 \\
\hline Partial & 3 & 4 & 3 & 10 \\
\hline Failed & 2 & 2 & 0 & 4 \\
\hline Total & 12 & 18 & 6 & 36 \\
\hline \multicolumn{5}{|c|}{ Kuwait } \\
\hline Success & 1 & 1 & 2 & 4 \\
\hline Partial & 1 & 3 & 4 & 8 \\
\hline Failed & 0 & 0 & 0 & 0 \\
\hline Total & 2 & 4 & 6 & 12 \\
\hline \multicolumn{5}{|c|}{ Qatar } \\
\hline Success & 3 & 6 & 15 & 24 \\
\hline Partial & 2 & 4 & 2 & 8 \\
\hline Failed & 2 & 1 & 1 & 4 \\
\hline Total & 7 & 11 & 18 & 36 \\
\hline \multicolumn{5}{|c|}{ Bahrain } \\
\hline Success & 17 & 10 & 5 & 32 \\
\hline Partial & 2 & 0 & 3 & 5 \\
\hline Failed & 0 & 0 & 0 & 0 \\
\hline
\end{tabular}




\begin{tabular}{|c|c|c|c|c|} 
Total & 19 & 10 & 8 & 37 \\
\hline \multicolumn{5}{|c|}{ Oman } \\
\hline Success & 0 & 2 & 0 & 2 \\
\hline Partial & 2 & 0 & 2 & 4 \\
\hline Failed & 0 & 0 & 0 & 0 \\
\hline Total & 2 & 2 & 2 & 6 \\
\hline
\end{tabular}

For the second research question (What is the relationship between team motivation of software engineers and project outcomes in the GCC countries and is the relationship similar across countries?), the relationship between team motivation and project outcome for all GGC countries was investigated using the Kruskal-Wallis test. The null hypothesis that there is no relationship between team motivation and project outcome was accepted, as there is no relationship between team motivation and project outcome (Kruskal-Wallis $\mathrm{U}=0.469 .5 ; p$ $=0.220$ ) in the six countries. None of the projects in Kuwait, UAE, and Bahrain completely failed. There is also no positive or negative connection between team motivation and project outcome, or if the project is more likely to be a success when the team feels more motivated. However, the plot graph in Figure 3 and Table 6 show that software engineers in Qatar tend to be different from their counterparts in the other GCC countries; Qatari software engineers are highly motivated when the project is successful, compared with other countries. Nevertheless, when the scale is collapsed to three (low, average, high), Qatari team motivation data failed to show a relationship between motivation and project outcome (Fisher's Exact Test sig. $=0.151$; Kruskal-Wallis sig. $=0.094)$. this is related to the low number of failed projects in Qatar. If there were more failed projects, the results might show a relationship between the two variables.

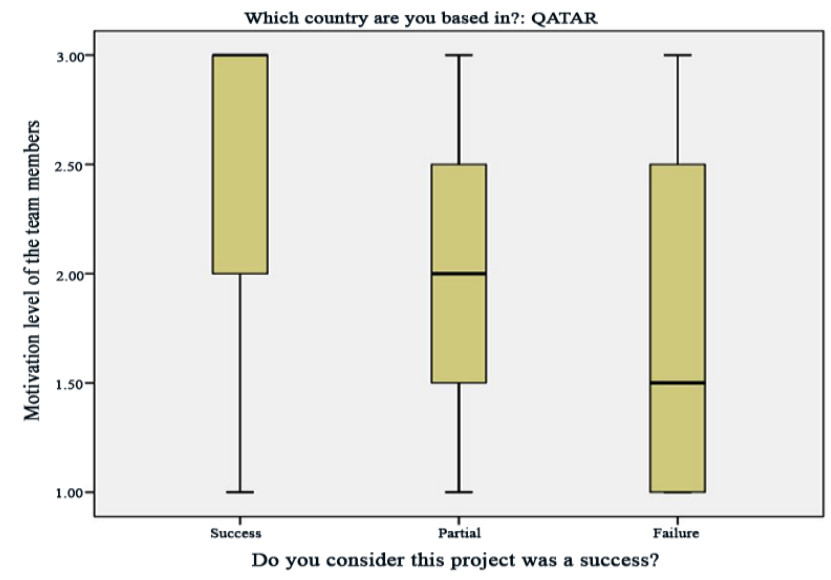

Figure 3: Motivation level and project outcome for Qatar
None of the respondents from Kuwait, UAE, and Bahrain noted any failed projects, and their motivational level was high, average, and low, respectively, for all projects. It seems that they are hesitant to talk about any of their failed projects and talk only about their successful projects. Therefore, it was hard to find any positive or negative relationship between motivation level and project outcome.

\subsection{Comparison to previous results}

Comparing the results with those of Verner et al. [7], Qatar has similar data to their Vietnamese counterparts. Where Verner $e t$ $a l$. did not reject the null hypothesis, arguing that Vietnam has a much higher percentage of highly motivated teams when the project is successful compared with other countries, such as Australia, the United States, and Chile [7]. The idea is the same in this research, as there is a much higher percentage of highly motivated software engineers in Qatar than in other countries when the project is successful. Although team motivation levels have been higher for successful projects based on the research results in the GCC countries, the author rejects the idea that motivation has a significant relationship with project outcome for all countries.

An interesting point is that all of Bahrain's projects are considered to be successful, but their motivational level is still low. This could be due to the lack of motivational factors, which are discussed in the next section. Additional testing was conducted on successful projects $(\mathrm{N}=110)$ because more than two-thirds of the projects in this research sample were considered successful. There were insufficient sample sizes at the country level to conduct significant testing for the partially successful and unsuccessful project.

\subsection{Motivation factors and motivation levels}

For the third question (What factors contribute to software engineer motivation in the GCC countries? Are these factors the same across countries?), motivational factors were investigated. There are four categories of factors that could influence motivation: project manager, software development, external, and practitioner factors. No factors are correlated with motivation in all six countries, some are not related at all, and some are only related only to particular countries.

A total of 14 factors were considered to be overall team motivational factors for at least some of GGC countries (Table 7). Some factors are significantly associated with motivation in two countries but not others. Project manager's communication and level of confidence are significantly related to motivational levels in Qatar and Bahrain. Some are significantly associated with motivation in only one country: working environment and teamwork in Qatar and the project itself in Bahrain. None of the factors were significantly related to the UAE, KSA, or Kuwait. Overall, all of the factors were significantly related to the motivation level of software engineers. Thus, these factors should be taken into consideration when working with software engineers in the GCC countries.

Table 7: Factors significantly associated with team members in each country and overall

\begin{tabular}{|c|c|c|c|c|c|c|}
\hline \multirow{2}{*}{ Motivational factors } & \multicolumn{6}{|c|}{ Team motivation factors } \\
\hline & Overall & UAE & KSA & Kuwait & Qatar & Bahrain \\
\hline \multicolumn{7}{|l|}{ PM factors } \\
\hline PM communication & 0.003 & 0.508 & 0.806 & 0.616 & 0.021 & 0.032 \\
\hline How good is PM & 0.018 & 0.637 & 0.679 & 0.616 & 0.064 & 0.643 \\
\hline Software development fac & & & & & & \\
\hline
\end{tabular}




\begin{tabular}{|c|c|c|c|c|c|c|}
\hline Was defined develop methodology used & $\mathbf{0 . 0 4 4}$ & 0.682 & 0.754 & 1.000 & 1.000 & 0.054 \\
\hline Risk identified at the start of project & $\mathbf{0 . 0 2 0}$ & 0.057 & 1.000 & 0.636 & 0.138 & 0.490 \\
\hline Risk assessed and controlled, managed & $\mathbf{0 . 0 3 7}$ & 0.523 & 0.148 & 0.289 & 0.075 & 0.778 \\
\hline External project factors & & & & & & \\
\hline Level of confidence in project & $\mathbf{0 . 0 0}$ & 0.862 & 0.101 & 0.379 & $\mathbf{0 . 0 0 8}$ & $\mathbf{0 . 0 0 5}$ \\
\hline Customer expectation & $\mathbf{0 . 0 3 5}$ & 0.222 & 0.466 & 0.519 & 0.468 & 0.199 \\
\hline Working environment & $\mathbf{0 . 0 0 1}$ & 0.148 & 0.686 & 0.684 & $\mathbf{0 . 0 3 3}$ & 0.274 \\
\hline Practitioner factor & & & & & & \\
\hline Project itself & $\mathbf{0 . 0 0 6}$ & 0.839 & 0.292 & 0.131 & 0.47 & $\mathbf{0 . 0 0 4}$ \\
\hline Technology used & $\mathbf{0 . 0 3 4}$ & 0.782 & 0.103 & 0.455 & 0.226 & 1.000 \\
\hline Reward at the end of the project & $\mathbf{0 . 0 0 0}$ & 0.511 & 0.169 & 0.419 & 0.097 & 0.216 \\
\hline Adequate staff & $\mathbf{0 . 0 1 3}$ & 0.237 & 0.1000 & 0.209 & 0.718 & 0.059 \\
\hline Key personnel & $\mathbf{0 . 0 1 7}$ & 0.098 & 0.237 & 0.209 & 0.686 & 0.120 \\
\hline Teamwork & $\mathbf{0 . 0 0 0}$ & 0.099 & 0.128 & 0.813 & $\mathbf{0 . 0 0 5}$ & 0.668 \\
\hline
\end{tabular}

\section{THREATS TO VALIDITY}

The questionnaire used in this research has been used successfully many times with other software developers from different countries [7],[13]. Therefore, this questionnaire is considered as a valid instrument for exploring motivational factors for software engineers, and using the same questionnaire allows us to compare results with previous studies. Because this research sample is bases on convenient sampling, not random sampling, the results are not as reliable as a random survey, as convenient samples might be biased. As this research was conducted in the GCC countries only, which is a small part of the world; the findings cannot be generalized and are limited to the sample population at the time the survey was conducted.

Ordinal data and a non-parametric statistic were used for the analysis. This study is reliable because the variables are taken from experienced software engineers who have knowledge of different software development projects. Limitations of the study include the small number of projects in Kuwait and particularly Oman and the low number of failed projects overall.

\section{CONCLUSION AND FUTURE RESEARCH.}

This study investigated the motivational factors that motivate the software engineering team in the GGC countries. It was found that software engineers in Qatar and Kuwait are mostly motivated when the project is successful, and Bahrain has the lowest level of motivation. Further, there is no relationship between team motivation and project outcome for GCC software engineers. These findings contradict the results of Verner et al. [7]. Although the previous study found six factors that motivate software engineers in the USA, Australia, Vietnam, and Chile [7], these factors were not relevant for software engineers in the GGC countries. Most of the factors used in this research are relevant to the GCC countries overall but were not specific to each country. The research results show that a lot of work needs to be done to motivate software engineer practitioners working in GCC countries, especially, the project manager who needs to have full authority to manage the project and be highly experienced.

To measure the relationship between motivation and project outcome, future research should investigate the same sample, with more data collected on failed projects. The results of the research can be valuable for project managers working in GGC countries as well as for global software projects in the same region.

\section{ACKNOWLEDGMENTS}

I would like to thank the Public Authority of Applied Education and Training (PAAET) and the manager of the research department for their support and understanding during the conduct of this research and for providing the funds needed to complete this research, Number Bs-17-10.

\section{REFERENCES}

[1] B. W. Boehm, Software Engineering Economics. Englewood Cliffs, NJ: Prentice-Hall, 1981.

[2] S. McConnell, "Avoiding classic mistakes [software engineering]," IEEE Software, vol. 13, no. 5, pp. 111-112, 1996.

[3] H. Sharp, N. Baddoo, S. Beecham, T. Hall and H. Robinson, "Models of motivation in software engineering," Information and Software Technology, vol. 51, no. 1, pp. 219-233, 2009.

[4] L. F. Capretz and F. Ahmad, "A call to promote soft skills in software engineering" Psychology and Cognitive Sciences Journal, vol. 4, no. 1: el-e3, 2018.

[5] S. Beecham, N. Baddoo, T. Hall and H. Sharp, "Motivation in software engineering: a systematic literature review," Information \& Software Technology, vol. 50, nos. 9-10, 860-878, 2008.

[6] A. C. C. Franca , D. E. S. Carneiro and F. Q. B. da Silva, "Towards an explanatory theory of motivation in software engineering: a qualitative case study of a small software company," in 26th Brazilian Symposium on Software Engineering (SBES), IEEE, pp. 61-70, 2012.

[7] J. M Verner, M. A. Barbar, N. Cerpa, S. Beechman and T. Hall, "Factors that motivate software engineering teams: A four country empirical study," Journal of Software and Systems, vol. 92, pp. 115-127, 2014.

[8] E. Andersen, "Never the twain shall meet: Exploring the 
differences between Japanese and Norwegian IS professionals," in Proceedings of the AAACM SIGCPR Conference on Computer Personnel Research, Kristiansand, Norway, pp. 65-71, 2002.

[9] R. Prikladnicki, J. L. Audy and R. Evaristo, "Global software development in practice: Lessons learned," Software Process Improvement and Practice, vol. 8, no. 4, 267-281, 2003.

[10] Rouibah, K., "Social usage of instant messaging by individuals outside the workplace in Kuwait; A structural equation model", Information Technology \& People, Vol. 21, No. 1, pp.: 34-68, 2008.

[11] M. Shokri-Ghasabeh and K. Kavoousi-Chabok, "Generic project success and project management success criteria and factors: Literature review and survey," WSEAS Transactions on Business and Economics, vol. 6, no. 8, pp. 456-468, 2009.

[12] K. R. Linberg, "Software developer perceptions about software project failure: A study", The Journal of Systems \& Software, vol. 49, nos. 2/3, pp. 177-192, 1999.

[13] J. M. Verner, S. Beecham and N. Cerpa, "Stakeholder dissonance: Disagreements on project outcome and its impact on team motivation across three countries," ACM SIGMIS, Vancouver, BC, pp. 25-33, 2010.

[14] J. D. Procaccino and J. M. Verner, "Software project managers and project success: An exploratory study," Journal of Systems and Software, vol. 79, no.11, pp. 15411551,2006

[15] J. D. Procaccino and J. M. Verner, "Software practitioner's perception of project success: A pilot study," International Journal of the Computer, The Internet and Management, vol. 10, no. 1, 20-30, 2002.

[16] ProjectLink. "Motivation House" [Online]. 2006. Availableon:http://www.projectlink.co.uk/whoweworkfor. htm

[17] S. Ramachandran and S. V. Rao, "An effort towards identifying occupational culture among information systems professionals," in Proceedings of the 2006 ACM SIGMIS CPR Conference on Computer Personnel Research, pp. 198-204, 2006.

[18] F. R. Tanner, "On motivating engineers," in Proceedings of the International Engineering Management Conference, pp. 214-218, 2003.

[19] T. Kaltio and A. Kinnula, "Deploying the defined software process," Software Process and Improvement Journal, vol. $5,65-83,2000$

[20] B. L. Mak and H. Sockel, "A confirmatory factor analysis of IS employee motivation and retention," Information \& Management, vol. 38, no. 5, 265-276, 2001.

[21] P. C. Lee, "The social context of turnover among information technology professional," in Proceedings of the 2002 ACM SIGCPR Conference on Computer Personnel Research, Kristiansand, Norway, pp. 145-153, 2002.

[22] R. Agarwal, and T. Ferrat, "Enduring practices for managing IT professionals," Communications of the ACM, vol. 45, no. 9, pp. 73-79, 2002.

[23] D. C. Smith and H. L. Speight, "Antecedents of turnover intention and actual turnover among information systems personnel in South Africa," in Proceedings of the ACM SIGNIS CPR Conference on Computer Personnel Research, Claremont, CA, 2006, pp. 123-129, 2006.

[24] AT Misirli, J Verner, J Markkula, M Oivo - "Factors Affecting Team Motivation: A Survey of Finnish Software Engineers," International Journal of Information System Modeling, vol. 6, issue. 3, pp. 1-26, 2015.

[25] Verner, J. M., \& Evanco, W. "In-house software development: What software project management practices lead to success?" IEEE Software, 22(1), 86-93, 2005.

[26] J. M. Verner and W. Evanco, "The state of the practice of software effort estimation in business organizations", In Proceedings of ESCOMSCOPE, pp. 149-15, April, Munich, Germany, 2000 